\title{
As convocações biopolíticas da imprensa em prol da cesariana
}

\section{The biopolitical calls of the press for caesarean section}

Las Ilamadas biopolíticas de la prensa a favor de la cesárea

Miriam Kenia de Carvalho ${ }^{1, a}$

miriamkenia@gmail.com | https://orcid.org/0000-0002-4148-3702

Rogério da Costa Santos ${ }^{1, b}$

rogcosta@pucsp.br | https://orcid.org/0000-0002-6807-4263

${ }^{1}$ Pontifícia Universidade Católica de São Paulo, Programa de Pós-Graduação em Comunicação e Semiótica. São Paulo, SP, Brasil.

a Mestrado em Comunicação e Semiótica pela Pontifícia Universidade Católica de São Paulo.

b Doutorado em História da Filosofia pela Université de Paris IV.

\section{Resumo}

Este artigo aborda a questão das convocações biopolíticas em torno das vias de nascimento, parto e cesariana, identificadas em dois grandes jornais de circulação nacional: Folha de S.Paulo e O Estado de S. Paulo. Considerados como dispositivos, segundo conceito adotado, esses veículos de mídia propagam o paradoxo: normal e seguro é fazer cesariana; estranho e arriscado é o parto normal. No entanto, mais do que propagarem o discurso em prol da cesariana, essas mídias convocam os leitores, com enunciados ancorados no medo, no controle do corpo e na bioeconomia. A constatação resultou da investigação conceitual realizada nas 390 reportagens sobre o tema publicadas nesses dois jornais entre 2010 a 2015 . O período é marcado pelo crescimento constante do número dessas cirurgias no Brasil, o que chegou a ser considerado uma epidemia pela Organização Mundial de Saúde.

Palavras-chave: Nascimento; Parto; Cesariana; Biopolítica; Comunicação; Dispositivos; Imprensa. 


\begin{abstract}
This article approaches the issue of biopolitical calls for the processof childbirth, to give birth spontaneouly or surgical procedure known as caesarean section, identified in two major newspapers having national circulation in Brazil: Folha de S.Paulo and O Estado de S. Paulo. Considered as devices, according with the concept taken into account in this study, these media vehicles propagate this paradox: Normal and safe is caesarean section. Strange and risky is normal birth. However, rather than propagating the discourse in favour of caesarean section, these media invite their readers to choose this surgery, with statements anchored in fear, body control and bioeconomy. The findings are resulted from the conceptual investigation conducted in the 390 articles on the theme published in these two newspapers between 2010 and 2015. The period is marked by the steady increasing number of these surgeries in Brazil, which was considered an epidemic by the World Health Organization.
\end{abstract}

Keywords: Childbirth; Delivery; Caesarean section; Biopolitics; Communication; Devices; Press.

\title{
Resumen
}

Este artículo aborda el tema de las llamadas biopolíticas acerca de las maneras como nacer, parto y cesárea, identificadas en dos importantes periódicos de difusión nacional en Brasil: Folha de S.Paulo y O Estado de S. Paulo. Considerados como dispositivos, según el concepto adoptado en este estudio, estos vehículos de comunicación propagan la paradoja: lo normal y seguro es la cesárea. Extraño y arriesgado es el parto normal. Sin embargo, más que propagar el discurso a favor de la cesárea, estos medios convocan a sus lectores, con declaraciones ancladas en el miedo, el control corporal y la bioeconomía. La conclusión a que se ha llegado resultó de la investigación conceptual realizada en los 390 artículos sobre el tema publicados en estos dos periódicos entre 2010 y 2015. El período está marcado por el crecimiento constante del número de estas cirugías en Brasil, fenómeno que la Organización Mundial de la Salud consideró una epidemia.

Palabras clave: Nacimiento; Parto; Cesárea; Biopolítica; Comunicación; Dispositivos; Prensa.

\author{
Contribuição dos autores: \\ Concepção e desenho do estudo: Miriam Kênia de Carvalho e Rogério Santos Costa. \\ Aquisição, análise ou interpretação dos dados: Miriam Kênia de Carvalho. \\ Redação do manuscrito: Miriam Kenia de Carvalho. \\ Revisão crítica do conteúdo intelectual: Rogério Santos da Costa. \\ Declaração de conflito de interesses: não há. \\ Fontes de financiamento: Conselho Nacional de Desenvolvimento Científico e Tecnológico (CNPq). \\ Considerações éticas: não há. \\ Agradecimentos/Contribuições adicionais: agradecemos as contribuições da professora Helena Katz, Doutora em \\ Comunicação e Semiótica pela Pontifícia Universidade Católica de São Paulo, Brasil.
}

Histórico do artigo: submetido: 12 ago. 2019 | aceito: 14 nov. 2019 | publicado: 30 jun. 2020.

Apresentação anterior: não houve.

Licença CC BY-NC atribuição não comercial. Com essa licença é permitido acessar, baixar (download), copiar, imprimir, compartilhar, reutilizar e distribuir os artigos, desde que para uso não comercial e com a citação da fonte, conferindo os devidos créditos de autoria e menção à Reciis. Nesses casos, nenhuma permissão é necessária por parte dos autores ou dos editores. 


\section{Introdução}

O número de cesarianas cresce em todo o mundo. Em 121 países, entre 1990 e 2014, a média global quase triplicou (de 6,7\% para 19,1\%). A expansão foi maior ainda na América Latina, passando de 22,8\% para 42,2\%1. "A cesariana é um procedimento cirúrgico que salva vidas quando certas complicações surgem durante a gravidez e o parto. No entanto, é uma cirurgia importante e está associada a riscos maternos e perinatais imediatos e pode ter implicações para futuras gestações, bem como efeitos em longo prazo que ainda estão sendo investigados”.1. O elevado índice dessas cirurgias no Brasil foi classificado como uma epidemia pela Organização Mundial de Saúde Pública (OMS)², ou seja, uma questão de saúde pública. Segundo a pesquisa "Nascer no Brasil”, coordenada pela Fundação Oswaldo Cruz - Fiocruz, em parceria com diversas instituições científicas, a cesariana é realizada em $52 \%$ dos nascimentos no Brasil, sendo que, no setor privado, a taxa é de $88 \%$. A recomendação da $\mathrm{OMS}^{2}$, de 2018, é de que somente $10 \%$ dos nascimentos sejam realizados por meio desse procedimento cirúrgico, o que representa o percentual que realmente tem indicação, considerando o critério clínico. "Os fatores que levam ao crescimento da cirurgia demonstram uma imbricada relação de elementos de naturezas distintas: políticos, econômicos, culturais, institucionais, profissionais, entre outros, que resultam na hipótese da normalização da cesariana como modo de nascer"4.

O artigo discorre sobre as convocações biopolíticas dos dispositivos de imprensa em prol da cesariana. A mídia mais do que propaga um discurso, os jornais convocam para o consumo da cirurgia eletiva. Em uma completa inversão das evidências cientificas, o nascimento cirúrgico com hora marcada é enunciado como a opção mais segura e viável. Em contraponto, o parto é apresentado como temeroso, arriscado e inadequado. Apesar de o excesso de cesarianas ser considerado uma epidemia, um caso de saúde pública, a mídia, como um dispositivo biopolítico, contribui para sustentar o Brasil entre os líderes no ranking dos países com as maiores taxas de cesariana do mundo, segundo a OMS5. Isso porque partimos da premissa de que "quanto mais a mídia fala de uma notícia, mais ela parece verdadeira”. Essa narrativa dos dispositivos midiáticos está alinhada com a análise da construção do pensamento que conduz a normalização da cesariana ${ }^{6}$. "Na cultura material que se constitui em torno da prática da cesariana, destitui-se a natureza como responsável pela experiência de fazer nascer. Para liberarem seus corpos e a si mesmas da responsabilidade pela parturição, as entrevistadas contam com as equipes médicas e as tecnologias, nas quais se deposita grande confiança"4.

Essa premissa teve como base a pesquisa conceitual realizada em reportagens sobre o tema que foram publicadas nos jornais Folha de S.Paulo (Folha) e O Estado S. Paulo (Estadão) no período de 2010 a 2015. A análise, com o foco na convocação, teve como fundamentação o conceito de dispositivo comunicacional proposto por Prado 7 , no qual há um simulacro de contrato comunicacional entre o enunciador (o jornalista na função de entidade institucional de autoria) e o enunciatário (o leitor com o perfil buscado pelo texto). O leitor não busca apenas se informar. O texto o apoia na sua busca para saber qual realidade é essa à qual ele pertence, como se integrar e como ela funciona. Tais indagações implicam modalizações de ser, de fazer, de poder. A narrativa do texto, que do ponto de vista do contrato aparece como uma troca, resulta, se vista a partir dos dispositivos, em uma convocação. Assim, a convocação "cria uma cena, um enquadramento a partir de uma palavra de ordem e, portanto, uma totalização discursiva baseada em certos valores"”.

Para isso, é preciso que o discurso encarne, que ele seja assumido do ponto de vista do corpo e não apenas em sua camada reflexiva. "A biopolítica, nessa fase midiática, orienta cada um para construir sua vida a partir dessas convocações discursivas que encarnam, pois são empuxos pulsionais, ligados à fantasia". E como esses jornais fazem as suas convocações em prol da cesariana? Ao normalizar a cirurgia como a via mais segura, em detrimento do parto, apresentado como arriscado, temido e estranho, os jornais atuam como importantes dispositivos enunciadores que convocam. Ao se despertar o medo pelo parto no corpo, favorece-se a escolha da cesariana e, dessa forma, constrói-se e consolida-se a hegemonia cesarista no modelo de assistência obstétrica brasileira. 
E por que essa é uma convocação biopolítica? De fato, a cesariana representa o modelo de assistência obstétrica que melhor atende ao sistema econômico e político atual, pois garante a gestão eficiente das agendas da mulher, dos profissionais de saúde e dos hospitais, além de possibilitar o total controle e previsibilidade das receitas dos planos de saúde. Por se tratar de um modelo focado na otimização e produtividade do corpo, atua em oposição ao parto que está imerso na imprevisibilidade, pois varia desde a data prevista até a sua duração, que pode se arrastar por longas horas, ocupando de maneira incerta leitos de hospital e alterando a agenda dos médicos.

O sociólogo inglês Nikolas Rose define que a política da vida atual vai além daquela que Foucault descreve para o período entre os séculos XVIII e XX: "Ela não está delimitada nem pelos polos de doença e saúde, nem focalizada em eliminar patologias para proteger o destino da nação. Ao contrário, está preocupada com nossas crescentes capacidades de controlar, administrar, projetar, remodelar e modular as próprias capacidades vitais dos seres humanos enquanto criaturas viventes"8.

Assim, a biopolítica no nosso século tem como foco a conduta da vida em si mesma. Não a vida biológica, mas os modos de vida que se apoiam, evidentemente, no biológico. $\mathrm{O}$ ato de parir é um exemplo bem nítido da argumentação de $\operatorname{Rose}^{8}$ de que as tecnologias médicas deixaram de curar doenças, exclusivamente, e passaram a controlar os processos vitais do corpo. A hegemonia da cesariana no ato do nascimento pode entrar nesse rol de processos vitais controlados pelo aparato tecnológico hospitalar, assim como o excesso de exames no pré-natal. A gestação, até então, fisiológica passou a ser, completamente, determinada pela medicina, assim como o ato do nascimento. Nesse modelo, a mulher perde o protagonismo do parto. $\mathrm{O}$ corpo da mulher, com foco na maternidade, é objeto de poder há tempos. A partir do século XIX, quando o sexo da mulher ganhou relevância na medicina social, com as questões correlatas à maternidade, à amamentação e à concepção, foi ele, o corpo feminino, que prevaleceu como alvo das disciplinas do sexo9 ${ }^{9}$. Desde, então, entra em cena o médico, com o seu poder e prestígio ${ }^{9,10}$.

Aqui, porém, o que mais surpreende é o fato de o saber médico ganhar uma nova versão na biopolítica do nascimento. Nessa teia paradoxal que transforma o parto - um ato fisiológico - em uma prática estranha e arriscada e a cirurgia em um procedimento comum e seguro, o médico usa a seguinte estratégia: oculta o saber baseado em evidências científicas - que só recomenda uma cesariana para casos com complicações médicas - para fazer valer a sua autoridade no ato do nascimento. As elevadas taxas de cesarianas realizadas no Brasil mostram que a estratégia desse poder da autoridade médica funciona. As vantagens dessa prática cirúrgica são construídas na prática, conforme aponta pesquisa realizada com obstetras visando discutir a normalização da cesariana entre esses médicos ${ }^{11}$. "Pode-se entrever um estilo de pensamento no qual um fato científico - as vantagens da cesariana - é moldado na prática: eles sabem agir no momento certo, têm uma técnica trivial com riscos mitigados e são especialistas neste trabalho do parto; estão convencidos de que a cesárea é um modo normal de nascer e que a sua utilização pode ser cada vez mais ampliada. Mudar seu modo de agir obstétrico não está em questão; eles fazem aquilo que, na sua comunidade de práticas, no seu círculo de credibilidade, estabelece-se como o melhor" ${ }^{\prime 1}$.

Nesse contexto, os jornais pesquisados podem ser considerados dispositivos biopolíticos que convocam. Segundo Agamben ${ }^{12}$, esse termo é decisivo para o pensamento de Foucault: "É um conjunto heterogêneo, linguístico e não-linguístico, que inclui virtualmente qualquer coisa no mesmo título: discursos, instituições, edifícios, leis, medidas de polícia, proposições filosóficas etc.”. O autor ${ }^{12}$ acrescenta que o dispositivo tem sempre uma função estratégica que se insere numa relação de poder e, dessa forma, pode-se dizer que resulta do cruzamento de relações de poder e de relações de saber.

E como esses dispositivos fazem isso? Pela convocação, pela modalização. O dispositivo comunicacional, no contexto da convocação biopolítica em torno das vias de nascimento, é, na maioria das vezes, um propagador do medo em torno do ato fisiológico de nascer e, assim, provoca a mobilização. 
Este artigo apresenta uma série de reportagens que exemplificam essa modalização. Nas matérias analisadas, a convocação não, necessariamente, usa palavras de ordem, mas faz-se o discurso encarnar pelo medo. Ao ser interpelada, a pessoa tem que sentir o chamado no corpo, tem que responder com o corpo, o que significa que, ao sentir medo, ela está respondendo positivamente à convocação em questão aqui o conceito de corpo tem como referência a teoria Corpomidia de Katz e Greiner ${ }^{13}$, detalhada na seção Resultados e discussão.

A análise das reportagens considerou ainda que o medo é um autêntico mecanismo de controle social, mobilizador da ordem e da segurança ${ }^{14}$. A pesquisa da Fundação Oswaldo Cruz $^{3}$, por exemplo, mostra que $70 \%$ das mulheres inicialmente querem a parturição, mas, durante o pré-natal, sentem-se inseguras com essa via de nascimento. Assim, aceitam, sem questionamentos, sem uma segunda opinião, a indicação de cesariana no final da gestação. Esse processo sugere que foram convocadas pelo medo do parto.

Os recursos usados por esses dispositivos midiáticos contribuem para a normalização da cesariana como forma de nascer que reproduz um estilo de pensamento da comunidade de práticas dos obstetras, que conduzem um deslizamento do conceito de cesariana, um procedimento cirúrgico, para uma forma de parto normal, conforme apresentado por Nakano ${ }^{11}$.

Epassa a ser reivindicado pelas mulheres, como um poder sobre as escolhas feitas no processo de nascimento dos seus filhos, resultado de um sistema de normas e valores, permeável às tecnologias que remodelam um novo parto 4 . "No contexto mais amplo da biomedicalização da vida e da reprodução, a cesariana reapresenta o parto e o nascimento na sociedade, e reivindica-se como o modo normal de dar à luz"4.

\section{Metodologia}

Conforme já citado, foram identificadas as reportagens sobre o tema publicadas nos jornais Folha de S.Paulo e O Estado de S. Paulo no período de 2010 a 2015, coletando-se cerca de 390 que continham as palavras: parto, cesariana, cesáreo, cesárea, nascimento e a expressão 'dar à luz'. A definição dos veículos seguiu dois critérios: primeiro, a relevância dos dois jornais na capital paulista, onde estão as maternidades com maior índice de cesariana do país, já que, conforme levantamento da Secretaria Municipal de São Paulo ${ }^{15}$, em 2014, na rede de hospitais particulares, a taxa de nascimentos por meio da cirurgia chegou a cerca de $80 \%$. O segundo fator é que os dois jornais estão entre os maiores do Brasil: a Folha é o maior por média de circulação diária (impresso mais digital), 351.745 impressos diários em 2014, segundo o Instituto Verificador de Comunicação (IVC) e O Estadão é o quarto maior no ranking do IVC. A pesquisa foi feita por meio do acervo digital dos veículos, de acesso exclusivo para assinantes. Para facilitar o alinhamento com os dados disponíveis sobre o crescimento de cesariana no Brasil, foi estabelecido o nexo temporal de cinco anos no período de 2010 a 2015.

Após a identificação e seleção das reportagens sobre o tema, ficou evidente, porém, a necessidade de separá-las conforme o conteúdo editorial. Foram destacados dois blocos de matérias: Temático e Cotidiano, como ilustram a Tabela 1 e a 2. Assim, buscou-se evitar o erro na comparação em função de conteúdo distinto.

O primeiro bloco, que chamamos de Temático, reúne os textos que trazem o debate e/ou informações em torno do modelo de assistência obstétrica em si. Nele estão temas como: a hegemonia da cesariana, pesquisas sobre as vias de parto e seu impacto, os alertas da OMS sobre a epidemia de cirurgias e as medidas do governo para incentivar o parto normal. Em geral, essas reportagens são publicadas nos cadernos de política e saúde dos dois jornais. O segundo bloco engloba as reportagens classificadas em Cotidiano, reunindo as notícias do dia a dia: nascimento de filhos de famosos, novos serviços médicos, avanços tecnológicos, dentre outros fatos. Essas reportagens estão espalhadas por diversos editoriais, do noticiário policial ao esportivo. Nesse grupo Cotidiano encontramos a maior parte dos textos modalizadores de mapas cognitivos ${ }^{7}$, que são 
construídos com maior apelo emocional e uso de clichês com pessoas que simbolizam as situações citadas ${ }^{4}$. Todos esses recursos favorecem as convocações biopolíticas, a modulação dos corpos e dos sistemas vitais.

Tabela 1 - Classificação das reportagens da Folha de S.Paulo, entre 2010 e 2015 (acervo digital)

\begin{tabular}{lccc} 
Ano & Total & $\begin{array}{c}\text { Temático: } \\
\text { quantidade/ } \\
\text { \% no total }\end{array}$ & $\begin{array}{c}\text { Cotidiano: } \\
\text { quantidade/ } \\
\% \text { no total }\end{array}$ \\
\hline $\mathbf{2 0 1 0}$ & 14 & $7(50 \%)$ & $7(50 \%)$ \\
$\mathbf{2 0 1 1}$ & 28 & $12(42 \%)$ & $16(57 \%)$ \\
$\mathbf{2 0 1 2}$ & 22 & $9(40 \%)$ & $13(60 \%)$ \\
$\mathbf{2 0 1 3}$ & 38 & $16(42 \%)$ & $22(57 \%)$ \\
$\mathbf{2 0 1 4}$ & 64 & $25(39 \%)$ & $39(61 \%)$ \\
\hline
\end{tabular}

Fonte: Os autores (2019).

Tabela 2 - Classificação das reportagens de O Estado de S. Paulo, entre 2010 e 2015 (acervo digital)

\begin{tabular}{cccc} 
Ano & Total & $\begin{array}{c}\text { Temático } \\
\text { Quantidade/ } \\
\% \text { no total }\end{array}$ & $\begin{array}{c}\text { Cotidiano } \\
\text { Quantidade/ } \\
\% \text { no total }\end{array}$ \\
$\mathbf{2 0 1 0}$ & 21 & $13(62 \%)$ & $8(38 \%)$ \\
$\mathbf{2 0 1 1}$ & 22 & $13(59 \%)$ & $9(40,9 \%)$ \\
$\mathbf{2 0 1 2}$ & 25 & $15(60 \%)$ & $10(40 \%)$ \\
$\mathbf{2 0 1 3}$ & 24 & $15(71 \%)$ & $9(42 \%)$ \\
$\mathbf{2 0 1 4}$ & 26 & $16(61 \%)$ & $10(39 \%)$ \\
$\mathbf{2 0 1 5}$ & 38 & $21(55 \%)$ & $17(44,7 \%)$ \\
\hline
\end{tabular}

Fonte: Os autores (2019).

\section{Resultados e discussões}

Um dos recursos dos dispositivos para propagar a cesariana, amplamente identificado nas reportagens, é o uso das expressões 'parto cesariana' e 'parto cesáreo', presentes em ambos os grupos, Temático e Cotidiano, durante todo o período da pesquisa (2010 a 2015). Nessa comunicação é evidente um deslocamento da ação para a palavra e da palavra para ação. Há contaminação direta entre os dois termos, sendo que, nesse caso, cesariana ganha, dos vários sentidos envolvidos no parto, a espontaneidade, a naturalidade e a proximidade com o ato fisiológico; simultaneamente, perde, em parte, seu sentido de cirurgia, de intervenção clínica. Mas também o parto recebe sentidos com a palavra cesariana que lhe é acoplada. Assim, a ideia de que se torna controlado, previsível e indolor são agora seus novos atributos. Essa leitura midiática reforça a hipótese do seu papel como dispositivo biopolítico em prol da cesariana. "O parto vaginal é evento que pode acontecer independente da intervenção de outrem [...]. Porém, à medida que estilos de pensamento da biomedicina se fixam, o parto se desnaturaliza, é capturado pelos dispositivos de cálculo e gestão de riscos e se torna alvo de controle e intervenções médicas" ${ }^{11}$. 
Mas o discurso midiático deve se encarnar no corpo da mulher, deve fazer sentido no corpo para que sua decisão reflita seus sentimentos. Segundo Katz e Greiner ${ }^{13}$, autoras da teoria Corpomidia, o corpo não é um meio por onde a informação simplesmente passa, pois, toda informação que chega entra em negociação com as que lá já estão. O corpo, assim, é o resultado desses cruzamentos, e não um lugar onde elas são apenas abrigadas. Desse modo, olhar o corpo que se submete facilmente à cesariana representa olhar como o ambiente passou a constituir a sua materialidade. As informações do meio se instalam no corpo, o corpo alterado por elas continua a se relacionar com o meio, mas, agora, de outra maneira, o que leva a propor novas formas de troca. As informações capturadas pelo processo perceptivo, que as reconstrói, passam a fazer parte do corpo: são transformadas em corpo.

Como a comunicação se baseia no mesmo sistema conceitual que usamos para pensar e agir, a linguagem verbal se torna uma fonte importante de evidência do funcionamento do sistema; importante, porém não a única. Nosso sistema conceitual - que é encarnado e de raiz metafórica - ocupa um papel central, definindo as realidades cotidianas. Não há nada que esteja em um pensamento que não tenha estado também no sistema sensório-motor do corpo $^{13}$. Como explicam Katz e Greiner ${ }^{13}$, conceitos se tornam corpo, pois "não são apenas matéria do intelecto. Conceitos estruturam o que percebemos, como nos relacionamos com o mundo e com as outras pessoas, como nos comunicamos".

A junção de dois conceitos distintos, parto e cesariana ${ }^{16}$, favorece a normalização da cirurgia, em detrimento do ato do parir fisiológico. Assim como a imprensa que propaga o termo "parto cesariana" para descrever um nascimento cirúrgico, o médico também iguala a dualidade dos conceitos para descrever as suas atividades. Aqui vale considerar o papel dessa especialidade médica, o obstetra, para a rede de difusão da cesariana. Esse profissional atua de modo expressivo na produção da técnica e dos valores a ela associados, ao mesmo tempo que são produtos das mesmas técnicas de valores, segundo a perspectiva apresentada por Nakano, Bonan e Teixeira ${ }^{11}$.

Então, esses corpos que conceituam a parturição como uma operação também alteram esse ambiente. Basta observar como as técnicas para uma cesariana evoluíram nos últimos 40 anos, reduzindo seus riscos e sua complexidade. A evolução da técnica da cirurgia foi fundamental para a sua "boa aceitação" se desenvolveu como medida salvadora, excepcional, recurso extremo para lidar com partos muito difíceis. Entretanto, não é esse o sentido que lhe dão os obstetras contemporâneos: ela é reapresentada como uma forma de parto - diferente, mas também um parto. Enquanto no parto vaginal, o trabalho do parto é da mulher, na cesariana, o trabalho é do médico, o controle é dele, em duplo sentido: ele domina o conhecimento e a técnica de fazer, saber e poder" ${ }^{\prime 1}$.

A combinação de conceitos conflitantes faz com que eles pareçam quase a mesma coisa. O discurso hegemônico apropria-se de um novo termo, naturalizando o parto que não é parto. Pela repetição e popularização, esse discurso exerce o seu poder sutil de convencimento e, assim, corporifica, enraíza-se no corpo da mulher e, por que não dizer, do homem - isto é, convoca.

Vejamos alguns exemplos dessa junção conceitual 'parto cesariana'. O editorial "Excesso de cesarianas"17 (09/05/2010) da Folha de S.Paulo, que pondera justamente os riscos do crescimento das taxas da cirurgia, usa o termo "parto cesáreo" logo na abertura do texto: 


\section{Editoriais}

editoriais@uol.com.br

\section{Excesso de cesarianas}

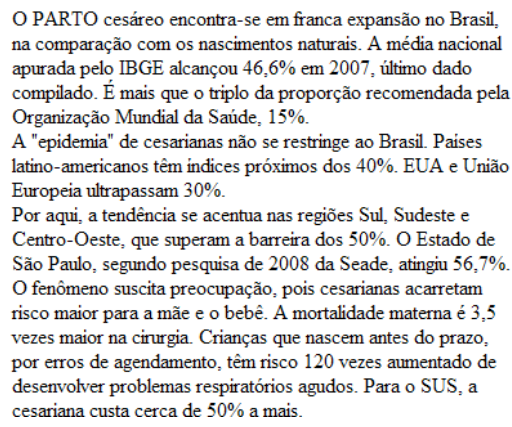

Figura 1 - Parto cesáreo

Fonte: Excesso de cesarianas (2010) ${ }^{17}$.

Nos anos seguintes, o paradoxo permanece nas páginas do jornal. Como exemplo, a matéria com o título: 'ANS não cobra planos por atendimentos feitos pelo SUS ${ }^{18}$, publicada em fevereiro de 2015:

\section{MAIS COMUM}

O tipo de intervenção mais ressarcida é o parto normal, seguida do parto cesariano e dos atendimentos de urgência. No parto norma o SUS recebe RS 443. Esses atendimentos podem custar o equivalente a 15\% de uma quimioterapia -no caso de leucemia crônica, c SUS paga RS 2.939 .

Em 2009, o TCU calculou que o valor a ser cobrado pelos procedimentos mais complexos seria até quatro vezes superior ao dos procedimentos menos complexos. Entre 2003 e 2007, por exemplo, os atendimentos mais caros teriam rendido cerca de R\$ 2,6 bilhões aos cofres do SUS.

Figura 2 - Parto cesáreo

Fonte: Amora e Cancian (2015) ${ }^{18}$.

Mesmo não sendo o objeto da investigação, mas pela relevância, vale citar exemplos fora do objeto dessa investigação, mas com ligação ao grupo de comunicação. Essa utilização é tamanha que a expressão é encontrada em jogos virtuais infantis direcionados para meninas. No portal UOL (2015), do Grupo Folha da Manhã, controlador também do jornal Folha de S.Paulo, na seção chamada Jogos de Meninas, na lista dos mais populares, é possível encontrar: Elsa Frozen Parto Cesariana ${ }^{19}$. Durante a partida, fica evidente que o nascimento não é um ato assumido pela mulher, a personagem da princesa Elsa. O protagonismo é do jogador, a criança, que faz o parto cesariana, no papel do médico. A terceirização do nascimento é também um dos pontos apresentados por Nakano, Bonan e Teixeira ${ }^{11}$ na discussão da normalização da cirurgia. Na cesariana, o trabalho de parto é do médico, o controle é dele.

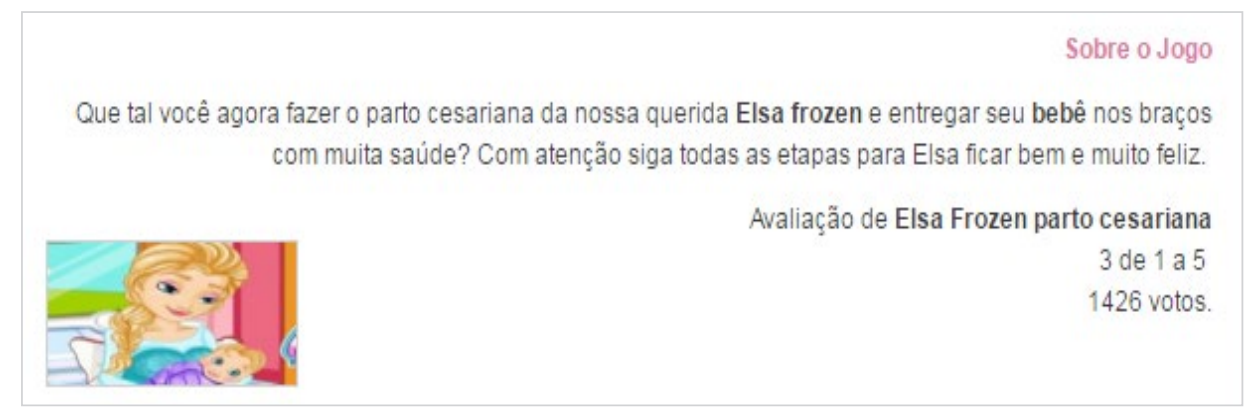

Figura 3 - Jogo Elza Frozen Parto Cesariana

Fonte: Elza Frozen... (2015) ${ }^{19}$. 
O emprego linguístico da expressão 'parto cesáreo' permeia aspectos psíquicos sociais e individuais, reforçados pela formação do obstetra, como explica Nakano, Bonan e Teixeira, na pesquisa sobre o estilo de pensamento da normalização do "parto cesáreo" entre obstetras ${ }^{11}$. "O investimento no desenvolvimento da técnica e da prática da cesárea acabou por favorecer a ampliação de seu uso; o aperfeiçoamento e a difusão da prática da cesariana promoveram a acumulação do capital sociocientífico, mobilizado por esses obstetras para o reconhecimento de si e de sua técnica"11.

Um dos obstetras mais renomados da capital paulista define a sua rotina profissional na reportagem "Saiba quem são e como é a rotina dos obstetras mais disputados de SP" ${ }^{20}$ da Folha de S.Paulo: "Ele não pode beber ou viajar quando bem entender, já que pode ser chamado para operar" (grifo dos autores), conta Abner Lobão Neto, que foi chefe do programa de pré-natal da Unifesp por 15 anos. O texto traz ainda a sua declaração afirmando que "adora fazer partos" ${ }^{20}$. Ou seja, adora fazer partos ou operar? Mais uma vez, a dualidade dá lugar ao sinônimo, como se operar e parto fossem a mesma coisa. Na pesquisa sobre a cultura da normalização das cesarianas em maternidades privadas, ficou constatado que essa dualidade também não causa estranhamento nas declarações das mulheres ${ }^{4}$. Os relatos mostram que é comum a utilização do verbo 'operar' com o mesmo sentido de parir ou de prestar assistência médica ao parto. "As mulheres o conjugam seja na primeira pessoa ('eu operei na maternidade X'), seja na terceira (os médicos 'operam' em tais maternidades e em tais dias). A incorporação da ideia do parto como evento cirúrgico não causa estranhamento"4.

\section{Significados do parto e da cesariana}

Assim como cresceram as reportagens sobre as epidemias de cesariana, também aumentaram as reportagens do cotidiano do nascimento associando o parto a fatos negativos das mais diversas ordens. Afinal, o biopoder não vacila. Na maior parte delas há uma narrativa emocional, associando-o aos fatos do dia a dia, às vivências pessoais, possibilitando uma identificação com o leitor. Essas reportagens seguem as características da mídia convocatória7 ${ }^{7}$, na qual a informação é apenas parte do texto, que é modulado a partir de valores de consumo mais amplos. A direção não é usar a informação como dado bruto. Dentre esses valores consumistas, a cesariana é a via mais alinhada com o sistema vigente. Relatos de mulheres apresentados no artigo A normalização da cesárea como modo de nascer: cultura material do parto em maternidades privadas no Sudeste do Brasil ${ }^{4}$ mostram que o risco da cirurgia é relativizado: "Outras necessidades concorrem a favor da cesariana, entre elas de gestão da vida produtiva e reprodutiva, de dimensão sócioafetiva e de consumo. O agendamento da cesárea, por exemplo, possibilita o afastamento planejado do trabalho e dos compromissos domésticos, com menor prejuízo ao desenvolvimento de tarefas e menos riscos de perda de posto. A 'marcação' também permite o planejamento da participação e celebração de amigos e familiares"4.

Cabe ressaltar que, nesse grupo de reportagens, há uma lógica ainda mais perversa midiática no uso polissêmico que foi criado para as palavras 'parto' e 'cesariana', pois, além da citação de 'parto cesáreo', há uma inversão estratégica nos títulos e textos das reportagens entre 'parto' e 'cesariana' conforme o teor da notícia veiculada. Também a palavra 'parto', não raro, substitui 'cesariana' no caso de notícias de intercorrência ou morbidade. Com isso, é reforçado o medo em torno do ato fisiológico e, simultaneamente, resguardado o mito da segurança maior na cesariana. Como nos aponta Marcondes Filho ${ }^{6}$, os "jornalistas dão a sua contribuição à desinformação quando se usam de termos indevidos, tendenciosamente minimizadores dos problemas ou exageradores de sua periculosidade".

Nessa trilha, os dispositivos midiáticos, no caso os jornalísticos, mais do que informar, buscam mapear, prescrever, convocar. Nessa convocação, reforçam o discurso de que o parto normal é temeroso; seguro é a cesariana. Essa estratégia reforça a normalização da cesariana4: "O repertório das mulheres sobre o parto vaginal é repleto de imagens negativas, veiculadas também em novelas, filmes, programas de televisão, matérias de revistas e outras mídias. As histórias sobre alguém que 'morreu de parto' ou um bebê que 'teve problemas por causa do 
parto', via de regra, referem-se a um parto vaginal"4. Nas Figuras 4, 5, 6 e 7, apesar de o título trazer a palavra "parto", ao ler a reportagem ou pesquisar sobre o caso, é possível identificar que os nascimentos foram realizados por meio de cesariana.

\section{vor notícias Ciência e Saúde}

Médico faz parto irregular e mãe e
bebê morrem, no interior de São
Paulo

Figura 4 - Parto e morte

Fonte: Médico faz parto irregular... (2015) ${ }^{21}$.

\section{cotidiano}

\section{Maternidade deve pagar babá para}

filhos de mãe morta no parto

RODRIGO VARGAS
DE CUIABA

09/07/2011 $\odot 0812$

Figura 5 - Mãe morta no parto

Fonte: Vargas (2012) 22 .

\section{Casa de Saúde é condenada por queda de bebê após o parto no \\ Rio}

Figura 6 - Queda após parto Fonte: Casa de saúde é condenada... (2012)23.

No centro da linguagem não está o ato normal, de plenitude de presença, intenção, contexto, mas o ato falho, que parasita de dentro da linguagem ${ }^{16}$. Um exemplo: a notícia ${ }^{24}$ de um bebê que teve o rosto cortado durante a cesariana, em o9 de novembro de 2011, em Manaus, foi publicada com a palavra "parto" em destaque no título e no primeiro parágrafo do texto. A palavra "cesariana" somente aparece no relato da família. O texto produzido pela Agência Estado foi reproduzido em vários veículos.

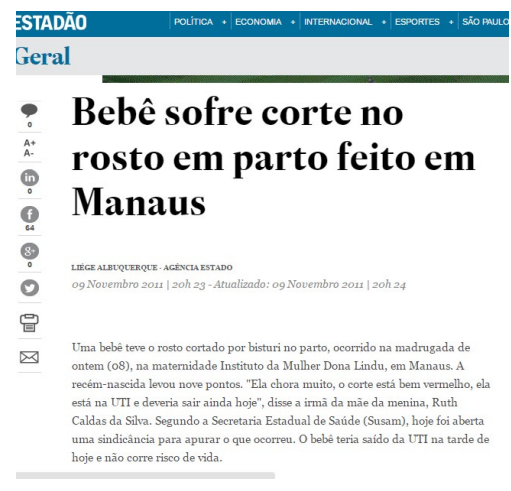

Figura 7 - Corte durante o parto

Fonte: Albuquerque (2011) ${ }^{24}$. 
O noticiário desse tipo de acidente cirúrgico permite verificar que poucas mudanças ocorreram de fato na construção do texto midiático sobre o parto no cotidiano dos nascimentos. Apesar da ampliação da divulgação de dados sobre os riscos da hegemonia cesarista e das políticas públicas para a sua redução, no período da pesquisa, as contradições seguem em destaque nesses dispositivos.

\section{O corpo grávido emocionado}

O papel de dispositivo comunicacional biopolítico das narrativas jornalísticas, que constroem os textos de grande parte das reportagens do bloco Cotidiano, é reforçado quando recorremos aos fenômenos emoção, sentimento e consciência e à sua relação com o corpo, segundo Damásio ${ }^{25}$. Em seu livro, esse autor demonstrou que uma série de experimentos, tanto em ratos quanto em seres humanos, confirma que a evocação de fatos novos é intensificada pela presença de certos graus de emoção durante o aprendizado. $\mathrm{O}$ autor ${ }^{25}$ exemplifica: "Se contarem a você duas histórias com mais ou menos a mesma extensão, com um número comparável de fatos, que diferem somente porque em uma delas os fatos têm alto conteúdo emocional, você se lembrará de um número bem maior de detalhes da história emocional do que da outra".

Pode-se inferir que a expansão do grupo de matérias com tom emocional que retratam o ato de nascimento tem relevância direta na propagação do medo diante da parturição. Esse recurso é utilizado em larga escala e, como ressalta Marcondes Filho 6 , "as informações aproveitam-se de emoções, preconceitos, medos e estruturas de pensamento predeterminadas e podem, a partir disto, serem recebidas sem especial exercício de reflexão". É comum se associarem problemas neurológicos ao parto: os jornais Folha de S.Paulo e O Estado de S. Paulo, por exemplo, creditaram à tentativa de parir a causa da paralisia cerebral de um bebê, por anoxia, em uma reportagem muito emotiva, publicada em 15 de outubro de $2015^{26}$. Vale ressaltar, a princípio, que a anoxia pode ocorrer independentemente da via do nascimento. No caso citado, apesar de o texto praticamente omitir essa informação, o bebê nasceu via cesariana. A reportagem é sobre um casal de jovens pais que promoveram um rodízio para dividir os cuidados com a recém-nascida que chorava muito e que somente se acalmava ao ser ninada no colo, com um balanço ritmado. Cansados, enviaram um convite, pelas redes sociais, para os amigos os ajudarem a niná-la e o comovente apelo foi amplamente aceito até por desconhecidos. $\mathrm{O}$ texto das reportagens foi acompanhado de lindas fotos na casa da família e, na edição digital da Folha de S.Paulo, há uma galeria com nove fotos, recurso fundamental para provocar emoções, sensibilizar.

\section{cotidiano}

\section{Pais criam rodízio de colo para ninar bebê com paralisia cerebral}

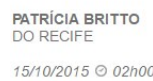

\section{CALOR HUMANO}

Os médicos afirmam que crianças com paralisia cerebral podem ser apáticas ou muito irritadiças. No caso de Olívia, outros fatores foram agravantes, como a privação do contato humano nos primeiros dias de vida. Ela nasceu de um parto difícil, que começou normal e virou cesárea de emergência. Olívia ficou cinco minutos sem respirar, o que bloqueou a oxigenação do cérebro, provocando uma lesão.

Figura 8 - Parto e paralisia cerebral

Fonte: Britto $(2015)^{26}$. 
Como Olivia precisa ficar entretida em um ritmo intenso, os pais colocam como trilha sonora rock dos anos 1960 e 1970, como Beatles. A condição do bebê se deve a uma lesão no cérebro provocada por um bloqueio na oxigenação durante o parto - ela chegou a ficar 5 minutos sem respirar. Ainda recém nascida, ela passou 48 dias na UTI e foi alimentada por sondas. Segundo o neurologista Saul Cypel, a privação de contato nesse período pode tê-la deixado mais irritadiça.

Figura 9 - Anoxia e parto

Fonte: Para ninar bebê... (2015) ${ }^{27}$.

A estratégia que sustenta esse tipo de reportagem é de que o receptor busca sentir as mesmas emoções que gostaria de poder viver na realidade, presenciando o fato ${ }^{6}$ : quando a imprensa lhe proporciona isso, quando ela o faz chegar às lágrimas, ele sente um conforto de ter participado do acontecimento. Isso lhe dá um valor de autenticidade, havendo uma substituição da verdade pela emoção. A questão, porém, é que as emoções podem ser manipuladas e provocadas de diversas maneiras, desde a definição do uso das palavras e conceitos, a escolha dos entrevistados até a produção técnica de fotos e imagens, sem que necessariamente o fato representado tenha sido tão emocionante assim. Dessa forma, os dispositivos midiáticos funcionam como indutores das emoções. Mais uma vez: convocam.

Com a interpretação dessas matérias emocionais, podemos retomar Damásio ${ }^{25}$. Para exemplificar os possíveis efeitos do uso da emoção no processo de aprendizado, conforme proposto por esse neurocientista, podemos usar duas matérias publicadas na Folha, num curto período, que citam o parto. Lembrando que esses dispositivos biopolíticos midiáticos conduzem ao aprendizado, à convocação, ou seja, à encarnação no corpo. Primeiro, consideremos a matéria citada acima, "Pais criam rodízio de colo para ninar bebê com paralisia cerebral" ${ }^{\prime 2}$, que faz parte do grupo das matérias Cotidiano, comparando-a com outra reportagem, do grupo Temático, com o título "Cirurgia eleva o risco de infecção, diz organização" ${ }^{2}$, publicada em 8 de setembro de 2015 (pouco mais de um mês antes da outra reportagem), exemplificada na Figura 10. Sem uso de fotos, esse texto traz orientação da OMS para redução de cesarianas em função do maior risco de infecção: apresenta dados sobre as cesarianas no Brasil e traz a declaração de uma pesquisadora que cita a dinâmica da cultura cesarista. Assim, não há na reportagem uma mulher que retrate essa vivência com uma história que emocione.

\section{Cirurgia eleva o risco de infecção, diz organização}

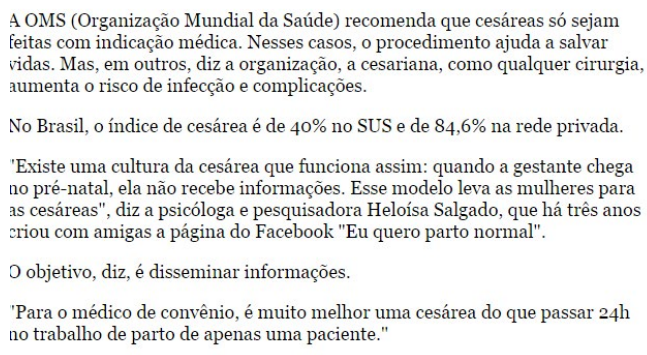

Figura 10 - Texto informativo

Fonte: Cirurgia eleva o risco de infecção... (2015) ${ }^{28}$. 
O leitor, diante dessas duas reportagens, segundo as premissas de Damásio ${ }^{25}$, lembrar-se-á mais facilmente da história do bebê choroso com paralisia cerebral causada pelo parto (a via de nascimento foi uma cesariana) ou do maior risco de infecção nas cesarianas? E qual emoção essa lembrança despertará em uma tomada de decisão?

Com esse olhar, também podemos analisar as reportagens carregadas de emoção que associam o parto domiciliar à morbidade. Só vale relembrar que a palavra 'parto' na primeira reportagem, "Pais criam rodízio de colo para ninar bebê com paralisia cerebral”26, foi usada para substituir a cesariana, que foi a via de nascimento.

Propagar o medo é uma estratégia certeira em prol da convocação para a escolha da cesariana. $\mathrm{O}$ temor em relação às complicações com o bebê e à dor no parto normal (geralmente amplificada pelas intervenções desnecessárias e os procedimentos de rotina hospitalar) é relevante para a tomada de decisão das mulheres sobre a via de nascimento. Segundo dados da Fundação Oswaldo Cruz ${ }^{3}$, entre as primigestas que utilizaram a rede pública, $83 \%$ citaram o medo como o principal fator para preferir a cesariana. Na rede privada, $69 \%$ apontaram a mesma justificativai. Neste contexto, voltamos à pesquisa de Nakabo, Bonan e Teixeira4: "Os temores que circundam o parto não se restringem à dor ou ao desconhecido - aqueles, passíveis de serem contornados com tecnologias analgésicas; estes, de serem conhecidos ou aprendidos em cursos pré-natais: há também o medo do incontrolável. As possibilidades do parto vaginal de escapar ao controle da mulher ou do profissional são tantas que a cesárea vai se apresentando como um parto mais adequado, passível de controle por meio de planejamento e de recursos tecnológicos". E como nos esclarece Damásio ${ }^{25}$ : "A presença obrigatória da emoção no processo de raciocínio pode ser vantajosa ou nefanda, dependendo das circunstâncias da decisão e da história pregressa de quem decide". As emoções - no caso, de medo - estão presentes na tomada de decisão e no modo como construímos nossa própria imagem.

O recurso emocional é usado também pelas revistas especializadas para esse público, como aponta Rezende $^{29}$. Ansiedade e medo são os sentimentos mais citados nas reportagens da Revista da Gestante, que geralmente suscita menção às emoções sobre o desenvolvimento do bebê e a aproximação do momento do parto. O sentimento de medo surge da possibilidade de que a experiência desconhecida seja problemática, difícil e dolorosa. A publicação, segundo a autora da pesquisa, aponta caminhos para evitar a dor. A revista aponta que o meio principal para controlar esses sentimentos é conversar com o obstetra e fazer exames. Dessa forma, reforça um movimento no qual a medicalização revela-se fonte de poder e reestruturação de relações.

\section{Considerações finais}

A expansão do número de reportagens mensurada nos dois jornais, apesar de ter um papel na divulgação em massa sobre as condições do nascimento do Brasil ainda não representa, na mesma proporção, mudanças significativas no paradoxo de como a parturição é retratada pela imprensa. Mesmo diante da ampliação da exposição sobre dados e riscos das cirurgias agendadas, a cesariana segue, como a via mais comum, segura, controlada, indolor e moderna. As convocações biopolíticas se fazem, cada vez, mais presentes. Assim, o jornalismo tem sido um poderoso dispositivo comunicacional em prol da cesariana, reproduzindo um estilo de pensamento que normaliza a cesariana como a vida de nascimento ${ }^{4}$.

Como pontua o historiador Antoine Prost ${ }^{30}$ : "Pela primeira vez na história da humanidade, agora as pessoas nascem e morrem num hospital. Antes de 1940, a imensa maioria das mulheres fazia o parto em casa; hoje, quase todos os partos são realizados na maternidade. É para lá que ela precisa ir quando não quer correr o risco de nenhuma complicação". Mas essa ida da mulher grávida ao hospital foi uma passagem construída, ao custo de uma mudança profunda na subjetividade feminina, que deslocou o sentido do nascimento no quarto de sua casa,

i A pesquisa acompanhou 23.984 mulheres e seus bebês em estabelecimentos de saúde públicos, conveniados ao SUS ou privados, que realizaram mais de 500 partos por ano, entre fevereiro de 2011 e outubro de 2012 . Foram coletados dados em 266 hospitais de 191 municípios das cinco regiões do país, incluindo as capitais e algumas cidades do interior. 
entre seus familiares e, portanto, tendo a experiência intensa de ser mãe num ato privado, para uma situação pública, em uma enfermaria ou em um centro cirúrgico, cenário asséptico, técnico e funcional. Aquilo que constituiu a rotina de nascimento de toda a humanidade até então, o nascimento domiciliar, torna-se algo temerário, arriscado e imprudente. Essa façanha da tecnomedicina não se restringe, evidentemente, ao ato do nascimento. A sofisticação dos equipamentos para diagnóstico e terapias acaba tornando o hospital o lugar adequado para tratar de todos os males. Simultaneamente, a medicina foi remodelada por sua intensa capitalização, como diz Rose, fruto "das exigências da seguridade pública ou privada, por seus critérios de reembolso e, em geral, por seu modo de lidar com a saúde e a doença como meramente outro campo para cálculo de lucros corporativos"

\section{Referências}

1. Betrán AP, Ye J, Moller AB, Zhang J, Gülmezoglu AM, Torloni MR. The increasing trend in caesarean section rates: global, regional and national estimates: 1990-2014. PLoS One. 2016 Feb 5;11(2):e0148343. doi:10.1371/journal.pone. 0148343

2. Organização Mundial da Saúde, Programa Especial de Pesquisa, Desenvolvimento e Treinamento em Pesquisa em Reprodução Humana. Declaração da OMS sobre taxas de cesáreas [Internet]. Genebra: A Organização; 2015 [citado em 2019 ago 12]. OMS no: WHO/RHR/15.02. Disponível em: https://apps. who.int/iris/bitstream/handle/10665/161442/WHO RHR 15.02 por.pdf?sequence=3

3. Nascer no Brasil: inquérito sobre parto e nascimento [Internet]. Rio de Janeiro: ESNP; 2014 [citado em 2019 ago 12]. Disponível em: http://www6.ensp.fiocruz.br/nascerbrasil

4. Nakano AR, Bonan C, Teixeira LA. A normalização da cesárea como modo de nascer: cultura material do parto em maternidades privadas no Sudeste do Brasil. Physis [Internet]. 2015 set. [citado 2019 out. 11] 25(3):885-904. Disponível em: https://bit.ly/2uoRvY2 doi: 10.1590/S0103-73312015000300011

5. Organização Mundial da Saúde, Programa Especial de Pesquisa, Desenvolvimento e Treinamento em Pesquisa em Reprodução Humana. Prevenção e eliminação de abusos, desrespeito e maus-tratos durante o parto em instituições de saúde [Internet]: Genebra: A Organização; 2014 [citado em 2019 ago 12]. OMS no: WHO/RHR/14.23. Disponivel em: https://www.who.int/reproductivehealth/topics/ maternal_perinatal/statement-childbirth/pt/

6. Marcondes Filho C. Comunicação e jornalismo: a saga dos cães perdidos. São Paulo: Hacker Editores; 2000.

7. Prado JLA. Convocações biopolíticas dos dispositivos comunicacionais. São Paulo: Educ; Fapesp; 2013.

8. Rose N. A política da própria vida: biomedicina, poder e subjetividade no século XXI. São Paulo: Paulus; 2013.

9. Foucault M. Microfísica do poder. Rio de Janeiro: Paz e Terra; 2014.

10. Foucault M. História da sexualidade 1: a vontade de saber. Rio de Janeiro: Paz e Terra; 2014.

11. Nakano AR, Bonan C, Teixeira LA. O trabalho de parto do obstetra: estilo de pensamento e normalização do "parto cesáreo" entre obstetras. Physis [Internet]. 2017 jul. [citado em 2019 out. 11];27(3):415-32. Disponível em: http://www.scielo.br/scielo.php?script=sci arttext\&pid=S010373312017000300415\&lng=en\%20doi:\%200.1590/s0103-73312017000300003

12. Agambem G. O amigo \& o que é um dispositivo. Chapecó: Argos; 2015.

13. Katz H, Greiner C. Corpo e processo de comunicação. Fronteiras Est Mid. 2001 dez;3(2):66-74.

14. Žižek S. Violência: seis reflexões laterais. São Paulo: Boitempo; 2014.

15. Secretaria Municipal da Saúde (SP), Coordenação de Epidemiologia e Informação. Nascer na cidade de São Paulo: 15 anos do SINASC. São Paulo: A Secretaria; 2015. 40 p. (Boletim CEInfo Análise; no 11).

16. Carvalho L. Eu não quero outra cesárea. São Paulo: Lexema; 2015.

17. Excesso de cesarianas [Internet]. Agora São Paulo (Grupo Folha). 2010 maio 09 [citado em 2019 ago 12]:Editorial. Disponível em: http://www.agora.uol.com.br/editorial/ult10112u732325.shtml 
18. Amora D, Cancian N. ANS não cobra planos por atendimentos feitos pelo SUS [Internet]. Folha de S.Paulo (Grupo Folha). 2015 fev. 08 [citado em 2019 ago 12]:Cotidiano. Disponível em: https://www1.folha.uol. com.br/cotidiano/2015/02/1586745-ans-nao-cobra-planos-por-atendimentos-feitos-no-sus.shtml

19. Elsa Frozen parto cesariana [jogo na Internet]. [Local desconhecido]: Jogos de Meninas; c1996-2019 [acesso em 2019 ago 12]. Disponível em: http://www.meusjogosdemeninas.com.br/jogo/elsa-frozenparto-cesariana

20. Echeverria M. Saiba quem são e como é a rotina dos obstetras mais disputados de SP [Internet]. Folha de S.Paulo (Grupo Folha). 2013 abr. 28 [citado em 2019 ago 12]:São Paulo. Disponível em: https:// www1.folha.uol.com.br/cotidiano/2015/02/1586745-ans-nao-cobra-planos-por-atendimentos-feitos-nosus.shtml

21. Médico faz parto irregular e mãe e bebê morrem, no interior de São Paulo [Internet]. Uol. 2015 jan. 21 [citado em 2019 abr. 10]:Notícia. Disponível em: https://noticias.uol.com.br/saude/ultimas-noticias/ estado/2015/01/21/medico-faz-parto-irregular-e-mae-e-bebe-morrem-no-interior-de-sao-paulo.htm

22. Vargas R. Maternidade deve pagar babá para mãe morta no parto [Internet]. Folha de S.Paulo (Grupo Folha). 2011 jul. 09 [citado 2019 ago 12]:Cotidiano. Disponível em: https://www1.folha.uol.com.br/ cotidiano/2011/07/941178-maternidade-deve-pagar-baba-para-filhos-de-mae-morta-no-parto.shtml

23. Casa de saúde é condenada por queda de bebê após o parto no Rio [Internet]. Estadão (Grupo Estado). 2012 jan. 03 [citado em 2019 ago 12]:Brasil. Disponível em: https://brasil.estadao.com.br/noticias/ geral,casa-de-saude-e-condenada-por-queda-de-bebe-apos-o-parto-no-rio,818199.

24. Albuquerque L. Bebê sofre corte no rosto em parto feito em Manaus [Internet]. Estadão (Grupo Estado). 2011 nov. 09 [citado 2019 ago 12]. Disponível em: https://www.estadao.com.br/noticias/geral,bebesofre-corte-no-rosto-em-parto-feito-em-manaus, 796713

25. Damásio A. O mistério da consciência do corpo e das emoções ao conhecimento de si mesmo. São Paulo: Companhia das Letras; 2015.

26. Britto P. Pais criam rodízio de colo para ninar bebê com paralisia cerebral [Internet]. Folha de S.Paulo (Grupo Folha). 2015 out. 15 [citado em 2019 ago 12]:Cotidiano. Disponível em: https://www1.folha.uol.com.br/ cotidiano/2015/10/1694185-pais-criam-rodizio-de-colo-para-ninar-bebe-com-paralisia-cerebral.shtml

27. Para ninar bebê com paralisia cerebral, pais contam com rodízio de colo [Internet]. Yahoo! Vida e Estilo. 2015 out. 16 [citado em 2019 ago 12]. Disponível em: https://br.vida-estilo.yahoo.com/ post/131293092135/para-ninar-beb\%C3\%AA-com-paralisia-cerebral-pais

28. Cirurgia eleva o risco de infecção, diz organização [Internet]. Folha de S.Paulo (Grupo Folha). 2015 set. 08 [citado em 2019 ago 12]:Cotidiano. Disponível em: https://www1.folha.uol.com.br/fsp/ cotidiano/232261-cirurgia-eleva-o-risco-de-infeccao-diz-organizacao.shtml

29. Rezende CB. Corpo e emoção na (re)produção de vidas: uma análise da Revista da Gestante [Internet]. In: 32a Encontro Anual da Anpocs; 2008 out. 27-31; Caxambu. São Paulo: Anpocs; 2008 [acesso em 2019 out. 15]. Disponível em: https://www.anpocs.com/index.php/encontros/papers/32-encontro-anualda-anpocs/gt-27/gt38-3/2687-claudiarezende/file

30. Prost A. As fronteiras e espaços do privado. In: Prost A, Vincent G, organizadores. História da vida privada, 5: da Primeira Guerra a nossos dias. São Paulo: Companhia das Letras; 2009. p.13. 